\title{
Lipoprotein Profile Modifications during Gestation: A Current Approach to Cardiovascular risk surrogate markers and Maternal-fetal Unit Complications
}

\section{Modificações do perfil lipoproteico durante a gestação: uma abordagem atual de marcadores sugestivos de risco cardiovascular e complicações materno-fetais}

\author{
Ana Paula Caires dos Santos ${ }^{1,2}$ Ricardo David Couto ${ }^{1,2}$ \\ ${ }^{1}$ Universidade Federal da Bahia (UFBA), Salvador, BA, Brazil \\ 2 Instituto Gonçalo Moniz, Fundação Oswaldo Cruz, Salvador, \\ BA, Brazil \\ Address for correspondence Ana Paula Caires dos Santos, \\ Universidade Federal da Bahia (UFBA), Rua Barão de Jeremoabo, \\ S/N, 40170-115, Ondina, Salvador, BA, Brazil \\ (e-mail: apcvalverde@gmail.com).
}

Rev Bras Ginecol Obstet 2018;40:281-286.

\begin{abstract}
Keywords

- lipid metabolism

- pregnancy

- cardiovascular diseases

- maternal-fetal complications

- dyslipidemia
\end{abstract}

\section{Resumo}

Several changes occur in lipid metabolism during gestation due to hormonal and metabolic changes, which are essential to satisfy the nutritional demands of the maternal-fetal unit development. The gestation shows two distinct periods that begin with fat accumulation, mainly in maternal adipose tissue, and the late phase, characterized by accelerated catabolism, with the increase of fatty acids in the circulation that causes hyperlipidemia, especially the one characterized as hypertriglyceridemia. Maternal hyperlipidemia may be associated with the development of maternal-fetal complications (preterm birth, preeclampsia, vascular complications) and the development of long-term cardiovascular disease. The cardiovascular risk may not only be related to lipoproteins cholesterol content, but also to the number and functionality of circulating lipoprotein particles. This review reports the major changes that occur in lipoprotein metabolism during pregnancy and that are associated with the development of dyslipidemias, lipoprotein atherogenic phenotype, and maternal-fetal unit complications.

Diversas mudanças ocorrem no metabolismo lipídico durante a gestação em função das alterações hormonais e metabólicas, que são essenciais para satisfazer a demanda nutricional ocasionada pelo desenvolvimento da unidade feto-placentária. O período da gestação apresenta dois momentos distintos que iniciam com acúmulo de gordura received October 17, 2017 accepted January 24, 2018 published online May 16, 2018
DOI https://doi.org/ 10.1055/s-0038-1642600. ISSN 0100-7203.
Copyright $\odot 2018$ by Thieme Revinter

Publicações Ltda, Rio de Janeiro, Brazil
License terms

c) $(1) \$$ 
principalmente no tecido adiposo materno, e a fase tardia, caracterizada por catabolismo acelerado, com aumento de ácidos graxos na circulação causando hiperlipide-

Palavras-chave

- metabolismo lipídico

- gravidez

- doenças cardiovasculares

- complicações materno-fetais

- dislipidemia mia, principalmente a aquela caracterizada como hipertrigliceridemia. A hiperlipidemia materna pode estar associada ao desenvolvimento de complicações materno-fetais (parto prematuro, pré-eclâmpsia, complicações vasculares) e de doenças cardiovasculares, a longo prazo. O risco pode estar relacionado não apenas ao teor de colesterol contido nas frações lipoprotéicas, mas também ao número e a funcionalidade das partículas lipoproteicas. Esta revisão aborda as principais mudanças que ocorrem no metabolismo lipoproteico durante a gravidez, e que estão associadas ao desenvolvimento de dislipidemias, fenótipo aterogênico e complicações maternofetais.

\section{Introduction}

During gestation, the maternal metabolism undergoes several transformations due to hormonal changes and nutritional demands. This period is characterized by changes in lipid metabolism that are essential to satisfy nutritional demands and fetal development., ${ }^{1,2}$ It has two distinct phases: the initial phase is characterized by fatty acids accumulation, which results in triglycerides deposition in the maternal adipose tissue; the late phase is characterized by accelerated adipose tissue catabolism with increased availability of fatty acids and glycerol in the circulation, which causes hypertriglyceridemia. ${ }^{3}$ Maternal hyperlipidemia, especially hypertriglyceridemia, may be associated with very low-density lipoprotein (VLDL) increased hepatic synthesis as a role of high estrogen concentration during gestation, and triglycerides (TG) rich lipoproteins catabolism reduction due to reduced lipoprotein lipase (LPL) and hepatic lipase (LH) activities. ${ }^{4-6}$ Such changes can provide development of atherogenic phenotype that is characterized by small and dense low-density lipoprotein (LDL) particles, associated with triglycerides levels increase, and a decrease of high-density lipoprotein (HDL) cholesterol levels. ${ }^{5}$

Maternal hyperlipidemia may be associated with fetal development complications (preterm birth, preeclampsia, vascular complications) and early cardiovascular diseases, when evaluated long term. ${ }^{3,5}$ In women, the progression and evolution of pregnancy represent an early opportunity to identify cardiovascular risk factors and serum markers. ${ }^{7}$ Studies suggest that gestation constitutes a "stress test" to the carbohydrates and lipids metabolic pathways, which causes inflammatory markers synthesis hyper-regulation and changes vascular function. Thus, this period may be the most adequate time for a long-term prediction of hemodynamic complications of the cardiocirculatory system. ${ }^{8-10}$

To better understand the lipoprotein metabolism changes that occur during pregnancy (especially those associated with the development of dyslipidemias with atherogenic phenotype and maternal-fetal complications), we reported here some metabolic implications, such as alterations of LPL and cholesterol ester transfer protein (CEPT), that are associated with cardiovascular risk increase during pregnancy, as well as the long-term repercussions of those changes that are related to pregnant woman and newborn health. To describe these major metabolic changes that occur during pregnancy, a literature review was performed by using scientific articles from the following databases: PUBMED, MEDLINE and SCIELO. The main health sciences descriptors (DeCS) were: cardiovascular diseases, lipid metabolism, lipoproteins, gestation, maternal-fetal complications, biomarkers, dyslipidemias and hypertriglyceridemia.

\section{Maternal Hyperlipidemia}

Pregnancy is characterized by hormonal changes such as progressive hyperinsulinemia, associated with estrogen, progesterone, cortisol, chorionic gonadotrophin and placental lactogen hormone increases, among other markers. On the other hand, serum adiponectin concentration is reduced. ${ }^{11}$ The major hormonal changes accountable for metabolic alterations are insulin resistance and the increased estrogen concentration. ${ }^{12}$ Lipoproteins and apolipoproteins serum concentrations increase significantly in pregnancy in response to hormonal changes. ${ }^{13,14}$ Estrogen increases hepatic VLDL synthesis, reduces hepatic lipoprotein lipase activity, and plays an important role in the accumulation of TG into HDL. ${ }^{6}$

Hypertriglyceridemia is the main manifestation associated with hormonal alterations due to increased adipose tissue lipolytic activity, which contributes to the physiological hyperlipidemia observed during pregnancy. ${ }^{11}$ This mechanism occurs mainly during the third trimester of pregnancy to ensure nutrient supply and essential fatty acids in adequate quantities to the placental-fetal unit. ${ }^{11}$ The mother's TG and non-esterified fatty acids concentrations show a positive correlation with the newborn's body mass. ${ }^{15,16}$ According to Emet et al $(2013)^{3}$ there are numerous changes in the lipid profile, especially in the third trimester of gestation. In their study, the total cholesterol (TC), low-density lipoprotein cholesterol (LDLC), TG and high-density lipoprotein cholesterol (HDL-C) mean value during the first trimester was significantly lower $(p<0.05)$ than in the third trimester of pregnancy. Wild et al (2016) $)^{17}$ affirm that these lipoprotein profile alterations may cause important clinical disorders. For example, severe hypertriglyceridemia may result in pancreatitis, and hypercholesterolemia may result in precocious atherosclerosis. 
Maternal hyperlipidemia, with hypertriglyceridemia, may be associated with reduced LPL activity at the end of gestation. Lipoprotein lipase drives the TG hydrolysis into TG-rich lipoproteins, such as chylomicrons and VLDL. The hydrolysis products, like glycerol and fatty acids, are mainly captured by the underlying tissue. The reduction of LPL activity leads to TG-rich lipoproteins accumulation by compromised lipoprotein catabolism. ${ }^{12,18}$ The significant increase in TG and LDL-C levels during gestation can be used as a biomarker of lipoprotein atherogenic phenotype to identify women at risk for developing cardiovascular atherogenic disease later in life. ${ }^{5}$

The hypertriglyceridemia during pregnancy is implicated in different types of lipid metabolism pathways modification. The CETP activity has been associated with increased HDL esterified cholesterol (EC) transfer to other lipoproteins. To maintain mass balance, while exchanging EC, HDL receives TG, by the action of CETP and phospholipid transfer protein (PLTP). Thus, the mass balance maintaining alter HDL particle composition and function. In addition, LDL particles become TG-richer, with a higher prevalence of smaller and denser LDL (sdLDL), phenotype B, more atherogenic. ${ }^{19,20}$ The sdLDL accumulation during pregnancy increases the risk of vascular endothelial damage. (-Fig. 1 $)^{1}$

\section{Cardiovascular Risk Biomarkers}

Cardiovascular risk may be related not only to the lipoproteins cholesterol content, but also to the number of circulating atherogenic particles that enter the arterial wall. ${ }^{21,22}$ Apolipoprotein B (apoB) and apolipoprotein A-I (apoA-I) serum concentrations can be used to calculate the apoB/apoA-I ratio, which has been used as a cardiovascular risk surrogate marker. ${ }^{23,24}$ It reflects the balance between circulating particles and represents the amount of cholesterol that reaches the tissues and is removed back to the liver. ${ }^{25,26}$ Besides, high HDL cholesterol content does not exclude the possibility of cardiovascular risk, the analysis of HDL biomarkers as apoA-I, which can be used to estimate the number of antiatherogenic particles, and HDL particles size must be performed. ${ }^{27}$ Consequently, serum
HDL-C determination plus HDL particle functionality should be performed as an essential protocol for cardiovascular risk assessment. $^{28,29}$ The determination of particle functionality brings the information about HDL function to exert antiatherogenic, antioxidant and antiinflammatory activities; in addition, it is possible to evaluate the performance of HDL on reverse cholesterol transport (RCT). By the way, the HDL protective function may be compromised in the presence of proinflammatory conditions that can cause lipoprotein structural modifications, such as in the presence of oxidative status. ${ }^{27}$

In addition to the structural and functional HDL evaluations, the determination of other biomarkers has been used, for example, the serum antioxidant potential can be measured from paraoxonase-1 activity (PON-1) (EC 3.1 0.8.1) determination, an enzyme belonging to the paraoxonase family. It is an enzyme associated with the HDL particle, esterase calciumdependent, synthesized by the liver, which contains 354 amino acids with molecular mass of $43 \mathrm{KDa} .{ }^{30,31}$ According to Aviram et al (2013), ${ }^{31}$ PON-1 has a protective action that supports the following functions: lipoproteins oxidative stress attenuation and reduced oxidized LDL macrophages uptake by stimulating HDL mediated cholesterol efflux. ${ }^{32,33}$

During pregnancy, all of these cardiovascular risk biomarkers, like apoA and apoB concentration, PON-1 activity, HDL and LDL particle size may be changed. Belo et al (2002) $)^{34}$ performed a longitudinal study in pregnant women. They concluded that there was an increase in apoB concentration in the third trimester of gestation, while apoA presented a slight reduction. They also observed an increased in sdLDL particle numbers at the end of gestation. ${ }^{34}$ Stefanovic et al $(2012)^{35}$ showed in a longitudinal study the PON-1 activity changes during normal gestation. There was a significant PON-1 activity reduction from the 32 nd week of gestation, thus a greater susceptibility to oxidative damage. ${ }^{35}$

\section{Maternal-fetal Complications}

The presence of abdominal obesity and hypertriglyceridemia in the first trimester of pregnancy are associated with an

\section{Gestational lipoprotein profile during third trimester}

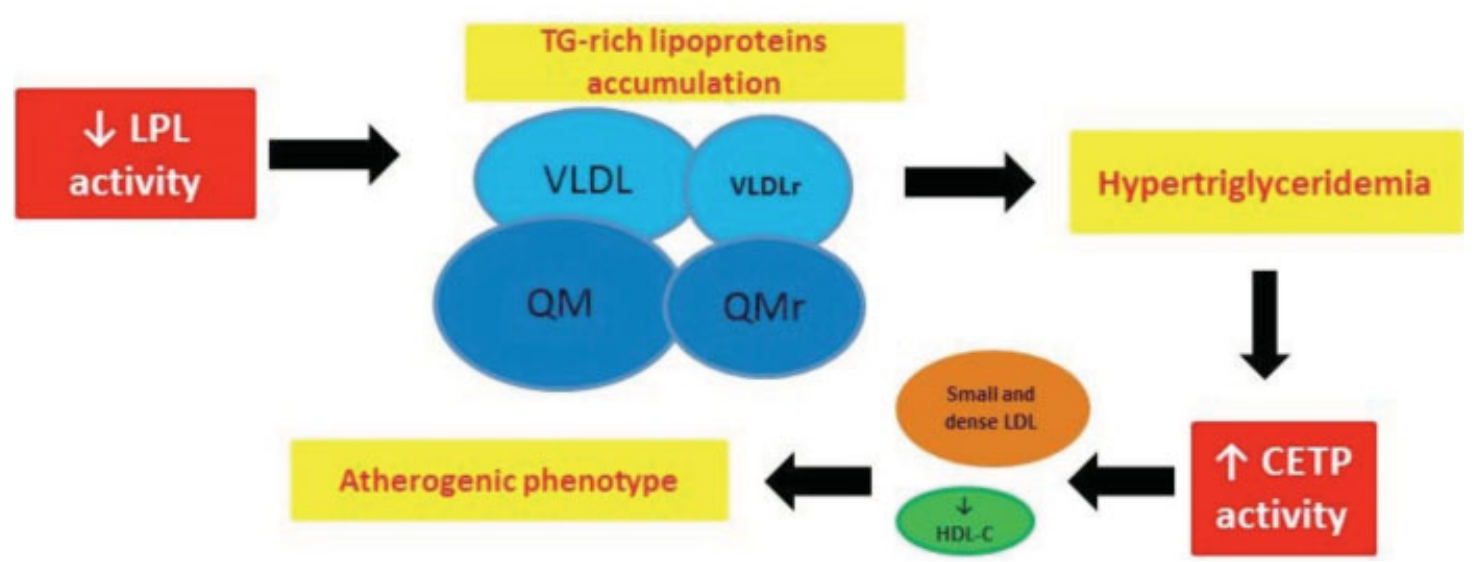

Fig. 1 The main changes that occur in the third trimester of gestation that contribute to cardiovascular diseases risk. Abbreviations: CETP, cholesterol ester transfer protein; HDL-C, high-density lipoprotein cholesterol; LDL, low-density lipoprotein; LPL, lipoprotein lipase; QM, chylomicron; QMr, remaining chylomicron; TG, triglycerides; VLDL, very low-density lipoprotein; VLDLr, very low-density lipoprotein receptor. Source: The author 
increased risk of developing glucose intolerance in the third trimester. Gestational diabetes is a public health priority, as it is a serious metabolic complication that aggressively impair both the mother's and the child's vital health. ${ }^{36}$

In obese pregnant women, hyperlipidemia is more pronounced. ${ }^{37,38}$ Total cholesterol (TC) and VLDL-C are in higher concentration, HDL cholesterol is reduced, and LDL lipoprotein is more susceptible to oxidation. ${ }^{39}$

The high TG concentration during pregnancy is associated with preeclampsia, preterm birth and cardiovascular disease increased risk. ${ }^{5,40}$ Pregnancy complications and adverse events in newborns are reported in hypertriglyceridemia and hypercholesterolemia cases. ${ }^{41,42}$ In addition, there is evidences that altered maternal lipid profile may be associated with congenital and developmental anomalies. ${ }^{43-46}$

The study by Han et al $(2016)^{45}$ concluded that pregnant women who developed gestational diabetes had an atherogenic lipid profile, such as a predominance of sdLDL particles, even before becoming pregnant.

There is a possible relationship between dyslipidemia, preterm delivery and maternal health risk in the long term. $^{40,47}$ The mechanisms that link preterm delivery to maternal cardiovascular risk are still not well understood, although the inflammatory process has been pointed out. ${ }^{8}$ The presence of inflammatory or proinflammatory phenotypes may predispose women to preterm birth during reproductive age, and it is also related to an increased risk of cardiovascular disease development in subsequent years. ${ }^{47,48}$

According to Smith et al (2001), ${ }^{48}$ women who have experienced preterm birth show two to three times greater risk of developing cardiovascular disease later in their lives. ${ }^{49}$ The evidence related to dyslipidemia, a precursor of cardiovascular disease, as well as preeclampsia, such as pregnancy physiologic changes are associated to metabolic abnormalities. ${ }^{50}$

To exemplify, - Table 1 shows the results achieved in the study of Jin et al $(2016)^{50}$ about the associations between maternal third-trimester TG concentration and pregnancy complications. They concluded that $7.6 \%$ of mothers developed gestational diabetes, $1.5 \%$ preeclampsia and $6.3 \%$ intrahepatic cholestasis of pregnancy. Every unit elevation of TG concentration in the third semester was associated with increased risk for gestational diabetes, preeclampsia and intrahepatic cholestasis of pregnancy. Serum TG concentration increased as pregnancy advanced $(p<0.001) .{ }^{50}$

Table 1 Associations between maternal third-trimester TG concentration and main pregnancy complications ${ }^{50}$

\begin{tabular}{|l|l|l|}
\hline Outcomes & \multicolumn{2}{|l|}{ TG $(\mathrm{mmol} / \mathrm{L})$} \\
\hline & AOR $(95 \% \mathrm{Cl})$ & $p$ value \\
\hline $\begin{array}{l}\text { Gestational diabetes } \\
\text { mellitus }\end{array}$ & $1.37(1.18-1.58)$ & 0.000 \\
\hline Preeclampsia & $1.50(1.16-1.93)$ & 0.002 \\
\hline $\begin{array}{l}\text { Intrahepatic cholestasis } \\
\text { of pregnancy }\end{array}$ & $1.28(1.09-1.51)$ & 0.002 \\
\hline Preterm birth & $1.04(0.77-1.38)$ & 0.818 \\
\hline
\end{tabular}

Abbreviations: AOR, adjusted odds ratio; TG, triglycerides.
There is an association between maternal hyperlipidemia, mainly hypertriglyceridemia, and preeclampsia. ${ }^{50,51}$ Elevated serum TG concentrations during pregnancy increases the risk of developing preeclampsia, as well as preterm birth. ${ }^{5}$ High TG concentrations are associated with a 4-fold preeclampsia increased risk when compared with women with normal TG concentrations, according to the lipid profile reference values. ${ }^{50-54}$ It is also known that high concentration of oxidative stress markers and reduction of antioxidant enzymes activity, such as PON-1, are highly associated to preeclampsia etiology. ${ }^{52}$

Studies have shown that hypertriglyceridemia together with maternal obesity, diabetes mellitus and hypertension, which characterize metabolic syndrome, correlate positively with preeclampsia. ${ }^{55,56}$ In addition, if these problems persist up to 6 months postpartum, they may influence future gestation as well as the cardiovascular risk long-term. ${ }^{20,57}$ Women who developed preeclampsia showed more changes in their lipid profile, like dyslipidemia, formation of particles more susceptible to oxidation and endothelial dysfunction. ${ }^{34,58,59}$ They also showed a more atherogenic lipid profile, with more marked hypertriglyceridemia, containing a greater sdLDL proportion, a more pronounced HDL-C and apoA-I reductions. ${ }^{60}$

\section{Conclusion}

The physiological changes in the cardiovascular system, proatherogenic lipid profile, changes in carbohydrate metabolism and PON-1 antioxidant profile contribute to the hypothesis that pregnant women are at higher risk of developing cardiovascular diseases later in their lives. Given the evidence, both particles number and lipoprotein structure, that is, the lipid composition and lipoprotein functionality, can be modified during the course of gestation. There is a need to find a better strategy to instruct the population about the risk of cardiovascular complications that could affect pregnant women long term so that the preventive and behavioral policies can be implemented. We suggest evaluating the lipid profile during the course of the trimesters of gestation to identify pregnant women at high risk of maternal-fetal and cardiovascular complications. Once the risk factors and markers have been identified, behavioral and nutritional changes must be introduced to achieve healthy and safe pregnancy outcomes in the long term.

\section{Conflicts of Interest}

The authors declare that there are no conflicts of interest.

\section{Acknowledgments}

We would like to thank the staff of the Clinical Biochemistry Laboratory, and the Faculty of Pharmacy of Universidade Federal da Bahia.

\section{References}

1 Winkler K, Wetzka B, Hoffmann MM, et al. Low density lipoprotein (LDL) subfractions during pregnancy: accumulation of buoyant LDL with advancing gestation. J Clin Endocrinol Metab 2000;85(12): 4543-4550. Doi: $10.1210 / j c .85 .12 .4543$ 
2 Wild R, Weedin EA, Wilson D. Dyslipidemia in pregnancy. Cardiol Clin 2015;33(02):209-215. Doi: 10.1016/j.ccl.2015.01.002

3 Emet T, Ustüner I, Güven SG, et al. Plasma lipids and lipoproteins during pregnancy and related pregnancy outcomes. Arch Gynecol Obstet 2013;288(01):49-55. Doi: 10.1007/s00404-013-2750-y

4 Kinoshita T, Shirai K, Itoh M. The level of pre-heparin serum lipoprotein lipase mass at different stages of pregnancy. Clin Chim Acta 2003;337(1-2):153-156. Doi: 10.1016/j.cccn.2003.08.002

5 Ghio A, Bertolotto A, Resi V, Volpe L, Di Cianni G. Triglyceride metabolism in pregnancy. Adv Clin Chem 2011;55:133-153. Doi: 10.1016/B978-0-12-387042-1.00007-1

6 Nelson SM, Matthews P, Poston L. Maternal metabolism and obesity: modifiable determinants of pregnancy outcome. Hum Reprod Update 2010;16(03):255-275. Doi: 10.1093/humupd/ dmp050

7 Hubel CA, Snaedal S, Ness RB, et al. Dyslipoproteinaemia in postmenopausal women with a history of eclampsia. BJOG 2000;107 (06):776-784. Doi: 10.1111/j.1471-0528.2000.tb13340.x

8 Sattar N, Greer IA. Pregnancy complications and maternal cardiovascular risk: opportunities for intervention and screening? BMJ 2002;325(7356):157-160. Doi: 10.1136/bmj.325.7356.157

9 Wolf G, Wenzel U, Stahl RA, Hüneke B. [Hypertensive disorders in pregnancy]Med Klin 2001;96:78-86. Doi: 10.1007/PL00002182

10 Rich-Edwards JW, Fraser A, Lawlor DA, Catov JM. Pregnancy characteristics and women's future cardiovascular health: an underused opportunity to improve women's health? Epidemiol Rev 2014;36:57-70. Doi: 10.1093/epirev/mxt006

11 Haghiac M, Basu S, Presley L, Serre D, Catalano PM, Hauguel-de Mouzon S. Patterns of adiponectin expression in term pregnancy: impact of obesity. J Clin Endocrinol Metab 2014;99(09): 3427-3434. Doi: 10.1210/jc.2013-4074

12 Herrera E, Ortega-Senovilla H. Disturbances in lipid metabolism in diabetic pregnancy - Are these the cause of the problem? Best Pract Res Clin Endocrinol Metab 2010;24(04):515-525. Doi: 10.1016/j.beem.2010.05.006

13 Butte NF. Carbohydrate and lipid metabolism in pregnancy: normal compared with gestational diabetes mellitus. Am J Clin Nutr 2000;71(5, Suppl)1256S-1261S

14 Ryckman KK, Spracklen CN, Smith CJ, Robinson JG, Saftlas AF. Maternal lipid levels during pregnancy and gestational diabetes: a systematic review and meta-analysis. BJOG 2015;122(05): 643-651. Doi: 10.1111/1471-0528.13261

15 Kitajima M, Oka S, Yasuhi I, Fukuda M, Rii Y, Ishimaru T. Maternal serum triglyceride at 24-32 weeks' gestation and newborn weight in nondiabetic women with positive diabetic screens. Obstet Gynecol 2001;97(5 Pt 1):776-780. Doi: 10.1016/S00297844(01)01328-X

16 Schaefer-Graf UM, Graf K, Kulbacka I, et al. Maternal lipids as strong determinants of fetal environment and growth in pregnancies with gestational diabetes mellitus. Diabetes Care 2008;31 (09):1858-1863. Doi: 10.2337/dc08-0039

17 Wild R, Weedin EA, Wilson D. Dyslipidemia in Pregnancy. Endocrinol Metab Clin North Am 2016;45(01):55-63. Doi: 10.1016/j. ecl.2015.09.004

18 Meyer BJ, Stewart FM, Brown EA, et al. Maternal obesity is associated with the formation of small dense LDL and hypoadiponectinemia in the third trimester. J Clin Endocrinol Metab 2013;98(02):643-652. Doi: 10.1210/jc.2012-3481

19 O'Brien TE, Ray JG, Chan WS. Maternal body mass index and the risk of preeclampsia: a systematic overview. Epidemiology 2003; 14(03):368-374

20 Barter PJ, Ballantyne CM, Carmena R, et al. Apo B versus cholesterol in estimating cardiovascular risk and in guiding therapy: report of the thirty-person/ten-country panel. J Intern Med 2006; 259(03):247-258. Doi: 10.1111/j.1365-2796.2006.01616.x

21 Pencina MJ, D’Agostino RB, Zdrojewski T, et al. Apolipoprotein B improves risk assessment of future coronary heart disease in the
Framingham Heart Study beyond LDL-C and non-HDL-C. Eur J Prev Cardiol 2015;22(10):1321-1327. Doi: 10.1177/2047487315569411

22 Forti N, Diament J. [Apolipoprotein B and A-I: cardiovascular risk factor?] Rev Assoc Med Bras (1992) 2007;53(03):276-282. Doi: 10.1590/S0104-42302007000300029

23 Kaneva AM, Potolitsyna NN, Bojko ER, Odland Jø. The apolipoprotein B/apolipoprotein A-I ratio as a potential marker of plasma atherogenicity. Dis Markers 2015;2015:591454

24 Thompson A, Danesh J. Associations between apolipoprotein B, apolipoprotein AI, the apolipoprotein B/AI ratio and coronary heart disease: a literature-based meta-analysis of prospective studies. J Intern Med 2006;259(05):481-492. Doi: 10.1111/ j.1365-2796.2006.01644.x

25 Tastet L, Capoulade R, Shen M, et al. Apolipoprotein B/apolipoprotein A-I ratio and progression of aortic valve stenosis - Results from the PROGRESSA Study. Circulation 2015;132:A18449

26 Bounafaa A, Berrougui H, Ikhlef S, et al. Alteration of HDL functionality and PON1 activities in acute coronary syndrome patients. Clin Biochem 2014;47(18):318-325. Doi: 10.1016/j. clinbiochem.2014.09.001

27 Rader DJ, Hovingh GK. HDL and cardiovascular disease. Lancet 2014; 384(9943):618-625. Doi: 10.1016/S0140-6736(14)61217-4

28 Kontush A. HDL particle number and size as predictors of cardiovascular disease. Front Pharmacol 2015;6:218. Doi: 10.3389/ fphar.2015.00218

29 Gelisgen R, Genc H, Kayali R, et al. Protein oxidation markers in women with and without gestational diabetes mellitus: a possible relation with paraoxonase activity. Diabetes Res Clin Pract 2011; 94(03):404-409. Doi: 10.1016/j.diabres.2011.08.001

30 Mackness MI, Mackness B, Durrington PN, Connelly PW, Hegele RA. Paraoxonase: biochemistry, genetics and relationship to plasma lipoproteins. Curr Opin Lipidol 1996;7(02):69-76. Doi: 10.1097/00041433-199604000-00004

31 Aviram M, Vaya J. Paraoxonase 1 activities, regulation, and interactions with atherosclerotic lesion. Curr Opin Lipidol 2013;24 (04):339-344. Doi: 10.1097/MOL.0b013e32835ffcfd

32 Kontush A, Chapman MJ. Antiatherogenic function of HDL particle subpopulations: focus on antioxidative activities. Curr Opin Lipidol 2010;21(04):312-318. Doi: 10.1097/MOL.0b013e32833bcdc1

33 Clausen TD, Mathiesen ER, Hansen T, et al. Overweight and the metabolic syndrome in adult offspring of women with diettreated gestational diabetes mellitus or type 1 diabetes. J Clin Endocrinol Metab 2009;94(07):2464-2470. Doi: 10.1210/ jc.2009-0305

34 Belo L, Caslake M, Gaffney D, et al. Changes in LDL size and HDL concentration in normal and preeclamptic pregnancies. Atherosclerosis 2002;162(02):425-432. Doi: 10.1016/S0021-9150(01) 00734-1

35 Stefanović A, Ardalic D, Kotur-Stevuljević J, et al. Longitudinal changes in PON1 activities, PON1 phenotype distribution and oxidative status throughout normal pregnancy. Reprod Toxicol 2012;33(01):20-26. Doi: 10.1016/j.reprotox.2011.10.009

36 Catalano PM. The impact of gestational diabetes and maternal obesity on the mother and her offspring. J Dev Orig Health Dis 2010;1(04):208-215. Doi: 10.1017/S2040174410000115

37 King JC. Maternal obesity, metabolism, and pregnancy outcomes. Annu Rev Nutr 2006;26:271-291. Doi: 10.1146/annurev. nutr.24.012003.132249

38 Sánchez-Vera I, Bonet B, Viana M, et al. Changes in plasma lipids and increased low-density lipoprotein susceptibility to oxidation in pregnancies complicated by gestational diabetes: consequences of obesity. Metabolism 2007;56(11):1527-1533. Doi: 10.1016/j.metabol.2007.06.020

39 Niromanesh S, Shirazi M, Dastgerdy E, Sharbaf FR, Shirazi M, Khazaeipour Z. Association of hypertriglyceridaemia with preeclampsia, preterm birth, gestational diabetes and uterine artery pulsatility index. Natl Med J India 2012;25(05):265-267 
40 Vrijkotte TGM, Krukziener N, Hutten BA, Vollebregt KC, van Eijsden M, Twickler MB. Maternal lipid profile during early pregnancy and pregnancy complications and outcomes: the ABCD study. J Clin Endocrinol Metab 2012;97(11):3917-3925. Doi: $10.1210 /$ jc.2012-1295

41 Catov JM, Ness RB, Wellons MF, Jacobs DR, Roberts JM, Gunderson EP. Prepregnancy lipids related to preterm birth risk: the coronary artery risk development in young adults study. J Clin Endocrinol Metab 2010;95(08):3711-3718. Doi: 10.1210/jc.2009-2028

42 Nederlof M, de Walle HEK, van Poppel MNM, Vrijkotte TGM, Gademan MGJ. Deviant early pregnancy maternal triglyceride levels and increased risk of congenital anomalies: a prospective community-based cohort study. BJOG 2015;122(09):1176-1183. Doi: 10.1111/1471-0528.13393

43 Smedts HPM, van Uitert EM, Valkenburg O, et al. A derangement of the maternal lipid profile is associated with an elevated risk of congenital heart disease in the offspring. Nutr Metab Cardiovasc Dis 2012;22(06):477-485. Doi: 10.1016/j.numecd.2010.07.016

44 Gupta S, Arora S, Trivedi SS, Singh R. Dyslipidemia in pregnancy may contribute to increased risk of neural tube defects -a pilot study in north Indian population. Indian J Clin Biochem 2009;24 (02):150-154. Doi: 10.1007/s12291-009-0027-9

45 Han ES, Krauss RM, Xu F, et al. Prepregnancy adverse lipid profile and subsequent risk of gestational diabetes. J Clin Endocrinol Metab 2016;101(07):2721-2727. Doi: 10.1210/jc.2015-3904

46 Catov JM, Bodnar LM, Kip KE, et al. Early pregnancy lipid concentrations and spontaneous preterm birth. Am J Obstet Gynecol 2007;197(06):610.e1-610.e7. Doi: 10.1016/j.ajog.2007.04.024

47 Chen X, Scholl TO. Maternal biomarkers of endothelial dysfunction and preterm delivery. PLoS One 2014;9(01):e85716. Doi: 10.1371/journal.pone.0085716

48 Smith GC, Pell JP, Walsh D. Pregnancy complications and maternal risk of ischaemic heart disease: a retrospective cohort study of 129,290 births. Lancet 2001;357(9273):2002-2006. Doi: 10.1016/ S0140-6736(00)05112-6

49 Ray CD, Shenoy JV, Hare AA. Pre-eclampsia and hyponatraemia.J Obstet Gynaecol 2006;26(07):695-696. Doi: 10.1080/01443610600929953

50 Jin WY, Lin SL, Hou RL, et al. Associations between maternal lipid profile and pregnancy complications and perinatal outcomes: a population-based study from China. BMC Pregnancy Childbirth 2016;16:60. Doi: 10.1186/s12884-016-0852-9

51 El Khouly NI, Sanad ZF, Saleh SA, Shabana AA, Elhalaby AF, Badr EE. Value of first-trimester serum lipid profile in early prediction of preeclampsia and its severity: A prospective cohort study. Hypertens Pregnancy 2016;35(01):73-81. Doi: 10.3109/10641955.2015.1115060

52 Genc H, Uzun H, Benian A, et al. Evaluation of oxidative stress markers in first trimester for assessment of preeclampsia risk. Arch Gynecol Obstet 2011;284(06):1367-1373. Doi: 10.1007/ s00404-011-1865-2

53 Demir B, Demir S, Atamer Y, et al. Serum levels of lipids, lipoproteins and paraoxonase activity in pre-eclampsia. J Int Med Res 2011;39 (04):1427-1431. Doi: 10.1177/147323001103900430

54 Baumfeld Y, Novack L, Wiznitzer A, et al. Pre-conception dyslipidemia is associated with development of preeclampsia and gestational Diabetes Mellitus. PLoS One 2015;10(10):e0139164. Doi: 10.1371 /journal.pone.0139164

55 Bryson CL, Ioannou GN, Rulyak SJ, Critchlow C. Association between gestational diabetes and pregnancy-induced hypertension. Am J Epidemiol 2003;158(12):1148-1153. Doi: 10.1093/ aje/kwg273

56 Ogura K, Miyatake T, Fukui O, Nakamura T, Kameda T, Yoshino G. Low-density lipoprotein particle diameter in normal pregnancy and preeclampsia. J Atheroscler Thromb 2002;9(01):42-47

57 Enquobahrie DA, Williams MA, Butler CL, Frederick IO, Miller RS, Luthy DA. Maternal plasma lipid concentrations in early pregnancy and risk of preeclampsia. Am J Hypertens 2004;17(07): 574-581. Doi: 10.1016/j.amjhyper.2004.03.666

58 Gratacós E, Casals E, Gómez O, et al. Increased susceptibility to low density lipoprotein oxidation in women with a history of preeclampsia. BJOG 2003;110(04):400-404. Doi: 10.1046/j.14710528.2003.02349.x

59 Sattar N, Gaw A, Packard CJ, Greer IA. Potential pathogenic roles of aberrant lipoprotein and fatty acid metabolism in pre-eclampsia. Br J Obstet Gynaecol 1996;103(07):614-620. Doi: 10.1111/ j.1471-0528.1996.tb09827.x

60 Duarte-Mote J, Perez-Torres C, Espinosa-López R, et al. [Relationship between dyslipidemia and severity in preeclampsia]. Rev Med Inst Mex Seguro Soc 2014;52(05):516-520 